\title{
The Role of Tech Companies in Economy and Environmental Protection using COVID-19 Pandemic (Case Study: Cisco Systems)
}

\author{
Majid Lotfi Ghahroud ${ }^{1 *}$, Hussein Aghajani Kalkhouran ${ }^{2}$, Hamed Besarati Ziabari ${ }^{3}$, \\ Mahdi Parseh ${ }^{4}$, Amir Sedighi ${ }^{5}$, Farhad Azizi ${ }^{6}$ \\ ${ }^{1}$ Social and Behavioral Science Department Financial Management, Faculty of Management, University of Tehran \\ ${ }^{2}$ Technical Consulting Center, Cisco systems \\ ${ }^{3}$ Persian Languae and Litrature Department, Allameh Tabataba i University \\ ${ }^{4}$ Tourism Management Department, Allameh Tabataba'i University \\ ${ }^{5}$ Business Management Department, Islamic Azad University \\ ${ }^{6}$ Department of Accounting, Islamic Azad University
}

\begin{abstract}
The global COVID-19 pandemic is of course not only a critical public health emergency, but a political, economic, and social emergency too. There is a huge number of private and public companies and even governments have changed their policies for their employees to work from home during COVID-19 pandemic. "Work from Home" is not a new way of working and it has been in some jobs for more than a decade; however, the COVID-19 pandemic has suddenly highlighted it. There are tech companies connecting employees and employers together by internet and they have significant role in the economy of counties worldwide. While COVID-19 pandemic has made their role became more prominent, their role in preserving the environment is clear. For example, they have reduced employees and students' Intra-city commute. In this article we show some benefits of online services by tech companies like Cisco systems during pandemic and then new statistics about number of new users of tech companies and their economical and environmental benefits.
\end{abstract}

Keywords: COVID-19 pandemic, Cisco Company

\section{Introduction}

Although this new pandemic crisis has some negative results on economy of many countries, it shows us some hidden part of truth. The role of tech companies to save world economy and, the impact of tech companies during this crisis on our environmental protection would be two main results of this new condition. In fact, these new and modern technological companies like Cisco systems not only can preserve our economy but can save our environment by some creative solutions. In this part, some of the main important effects of tech companies on economy and environment are shown. The question of how industrial companies can survive the impact of lockdowns and social distancing has raised after the COVID-19 pandemic in 2020 (Sheth, 2020). Businesses know how to make goods or services and offer them at both global as well as local levels. In fact, they are masters at developing awareness campaigns and persuading customers to purchase goods or services. These capabilities are shown by Vargo and Lusch (2004) in their service dominant logic (SDL). Generally, businesses are more efficient and effective compared to the capabilities of the government or non-profit organizations.

First, while after COVID-19 pandemic many businesses face with problems, just some companies like

Corresponding author: Majid Lotfi Ghahroud, Social and Behavioral Science Department Financial Management, Faculty of Management, University of Tehran, E-mail: majidlotfi@ut.ac.ir

https://doi.org/10.47277/JEEP/1(1)17 tech companies have better condition in this period. In fact, during the COVID-19 crisis we have witnessed the use of technology, such as WebEx and Zoom, between many businesses even the doctor and the patient. For example, the doctor or the healthcare provider can see many more patients online and the patients do not have to pay for the cost of traveling and waiting at the clinic (Sheth, 2020). COVID-19 was a great wake up for all businesses. It has clearly demonstrated how fragile most of businesses are. It has created disruption in many ways both domestically and globally, especially with respect to food and energy. It is hard to imagine how business could run today without smart phones, the internet, ecommerce, WebEx and Zoom meetings (Jackson, 2020).

Secondly, the tech companies also have helped to educational system as well. Since the effects of the COVID-19 crisis on education systems in south East Asia early in 2020, education companies and technology companies have built up their marketing of products to support online learning. Many companies, including videoconferencing and educational content providers like Cisco systems, have suggested some services for free for temporary periods to help education system. For example, in March 2020, some online education companies got better position in stock market rather than others (EdSurge, 2020).

Thirdly, COVID-19 has transformed our practice of palliative care and clinical medicine as we know it and change it to online. Telemedicine has emerged as an important technology to bring medical care to patients. Since attempting to reduce the transmission of COVID19 among patients and families, telemedicine is a great 
way to manage it (Calton et al., 2020). Actually, this way of treatment has many benefits and runs by tech companies. For example, Patients who receive medical care by this method are very satisfied with the convenience of video care and the can save more money and time as well (Calton et al., 2020).

Fourthly, tech companies in this new crisis not only have a significant role in our economy indirectly, but by using digital technology solutions for tracing, quarantine enforcement and movement permission, and social distancing monitoring have been showed their critical role in controlling COVID-19. Since traditional public health approach involving phases of containment (steps to prevent the virus from spreading), delay (measures to reduce the peak of impact), mitigation (providing the health system with necessary supports) and research (seeking additional effective measures and a cure), tech companies by digital technology can suggest new creative methods which are faster and more effective (Kitchin, 2020). Finally, as a matter of fact, COVID-19 has also showed that environmental sustainability (carbon footprint) is directly related to businesses since after pandemic we can see less pollutant substances. The air and water are cleaner in all areas of the world. In fact, air pollution is man-made and therefore reversible. In short, business, nature, and society are interdependent for mutual survival during the present threat of the COVID19 pandemic (Williamson et al., 2020).

\section{Cisco systems Inc}

Industrial high-tech markets not only are characterized by profound levels of market and technological uncertainty, but firms herein must navigate extraordinarily dynamic and fast-moving environments (Groeger and et al., 2019). Moreover, adapt and lead the agile development process would be one of the significant part of policy of this company (Chen, 2016). Also, Cisco systems as a very well-known tech company follow this business models, and their business models are highly integrated with its partner and supplier (Chesbrough \& Schwartz, 2007). Generally, when business strategy changes, factors of strategy execution had to change as well. In Cisco systems this policy is a fundamental process of company (Chatterjee, 2016). Cisco Systems, Inc. is an American multinational technology company. This huge tech company develops, manufactures and sells networking hardware, software, telecommunications equipment and other high-technology services and products. Cisco employs 66,000 people, there are actually at least another 200,000 individuals directly involved with Cisco's business activities such as partners and suppliers. Cisco has 70,000 direct partner relationships with external firms and leverages 24,000 Cisco certified ('CCIE') external engineers to help resolve issues and with design solutions for its customers. Also, Cisco has at least 129 direct competitors and 3000 direct suppliers and the number of employees in 2019 was 75,900 people (Cisco Annual report, 2019). These figures clearly show that the revenue of company has increased (48 billion Dollar to 51.9 billion Dollar) from 2017 t0 2019, and the most important part of revenue earned from Infrastructure platforms mainly in Americas. Also, we can see gross margin would be without any significant changes and operating cash flow has increased in 2019. The very important point in these figures is that the main part of capital is gathered by share repurchases. In addition, we can that dividend has being increased from 2017 and in 2019 is 1.33 Dollar per share. This figure clearly shows that the Cisco's total return in comparison with the S\&P 500 Index, and the S\&P Information Technology Index was higher in 2019. The reason could be related to COVID-19 and increase in the number of users. This huge company has some useful and applicable platforms like, such as OpenDNS, Webex, Jabber and Jasper, Cisco specializes in specific tech markets, such as the Internet of Things (IoT), domain security and energy management.

\section{Cisco systems and environmental protection}

Taking care of the planet is one of the main slogans in the company. Environmental sustainability is critical for economies and for all global citizens and Cisco systems follow this statement. In addition, reducing greenhouse gas emissions, preserving biodiversity and natural resources, and designing our products to minimize waste are some other aspect of environmental protection which is considered by Cisco systems. The company looks for opportunities to minimize Cisco's impact on the environment in every corner of business and supply chain and seeks ways technology can reduce energy use and greenhouse gas emissions.



\section{Revenue}

by product category and services

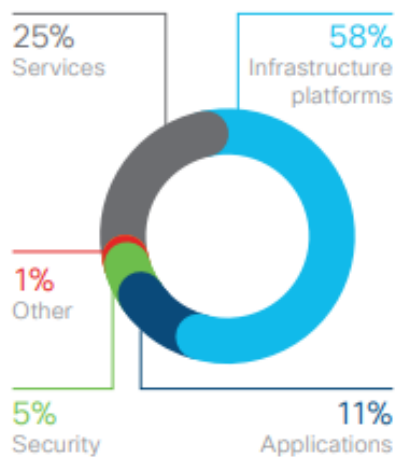

by geographical segment

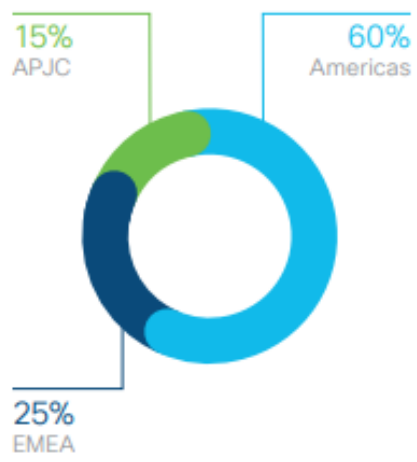


Figure1: Financial highlights for fiscal 2019 (Revenue), source: www.cisco.com

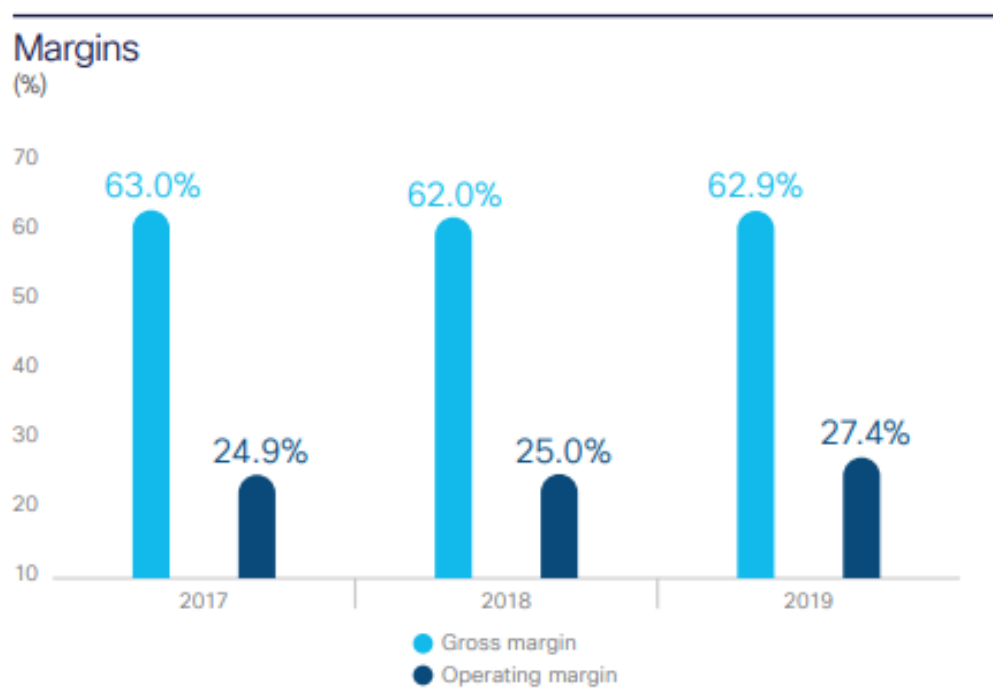

\section{Operating cash flow (\$B)}

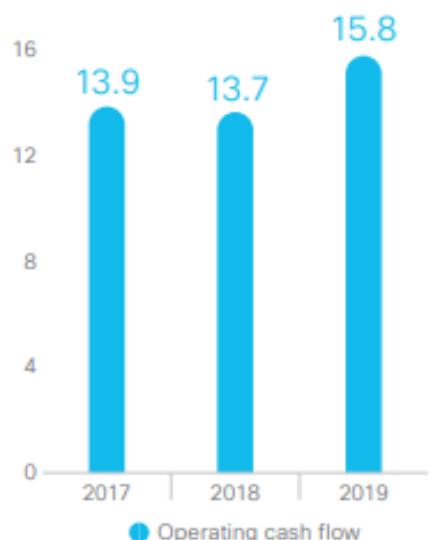

Figure 2. Financial highlights for fiscal 2019 (Margins and operating cash flow), source: www.cisco.com
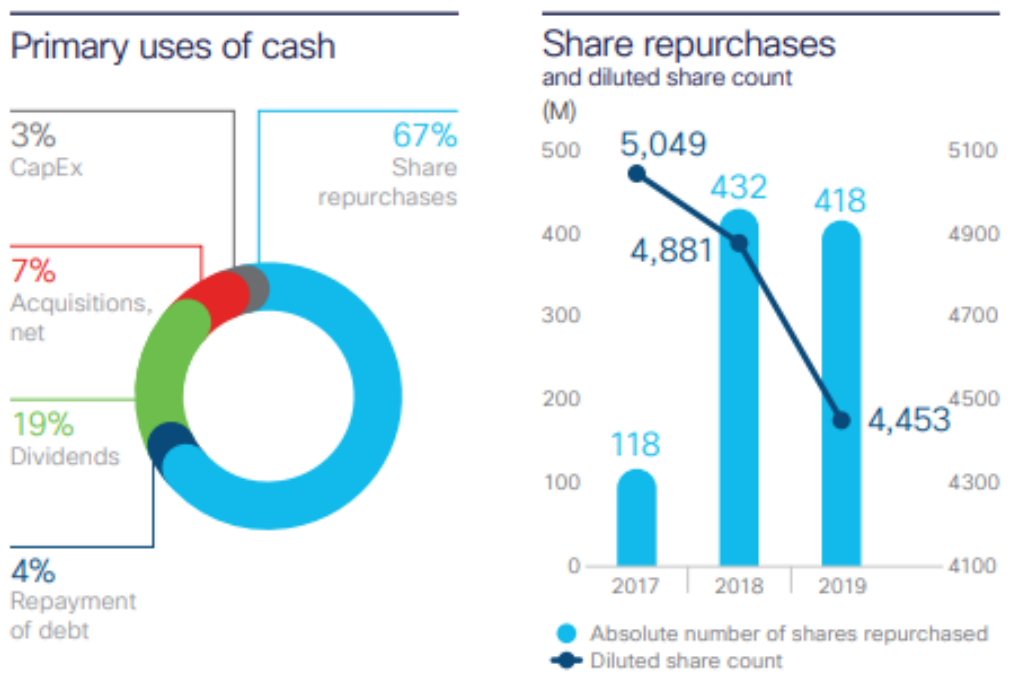

Dividends paid per share (\$)

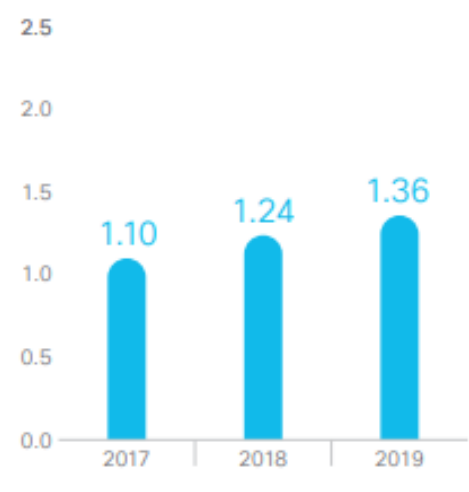

- Dividends paid per share

Figure 3: Financial highlights for fiscal 2019 (Capital allocation and share info), source: www.cisco.com

$\$ 250$

$\$ 200$

$\$ 150$

$\$ 100$

$\$ 50$

$\$ 0$

\begin{tabular}{|l|l|l|l|l|l|}
\hline July 2014 & July 2015 & July 2016 & July 2017 & July 2018 & July 2019
\end{tabular}

Figure 4: Comparison of 5-year cumulative total return (among Cisco Systems, Inc., the S\&P 500 Index, and the S\&P Information Technology Index), source: www.cisco.com 
Some of goals based on FY (Fiscal Year): (A) 49\% reduction in Scope 1 and 2 greenhouse gas emissions ( $82 \%$ of FY22 goal achieved) - Fiscal year 2022. (B) $83 \%$ of energy came from renewable sources $(98 \%$ of FY22 goal achieved) Fiscal year 2022. (C) 1M metric tonnes of supply chain greenhouse gas emissions avoided (115\% of FY20 goal achieved). Reduce total Cisco Scope 1 and 2 GHG emissions worldwide by 60 percent absolute by FY22 (FY07 baseline). Cisco systems Improves large rack-mounted equipment system power efficiency-as measured from the input power from the facility to the board-mounted ASICs, memory, and other chip devices-from 77 percent to 87 percent by 2022 (using FY16 baseline). Cisco systems Avoids 1 million metric tonnes of GHG emissions in our supply chain from FY12 to FY20. In fact, from 2012 this company has achieved more than $100 \%$ of goal.

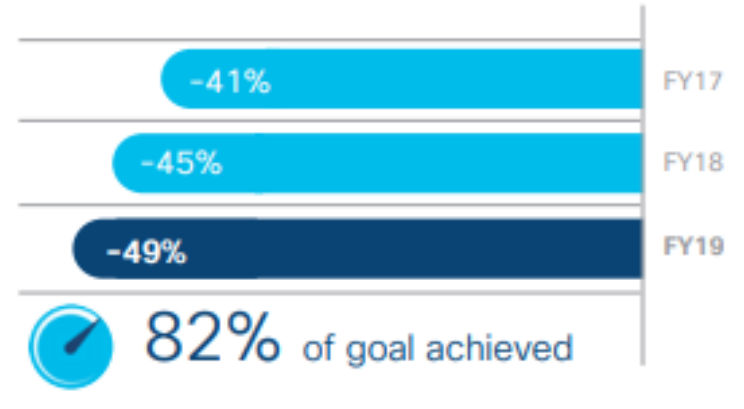

Figure 5: GHG emissions reduction, source: www.cisco.com

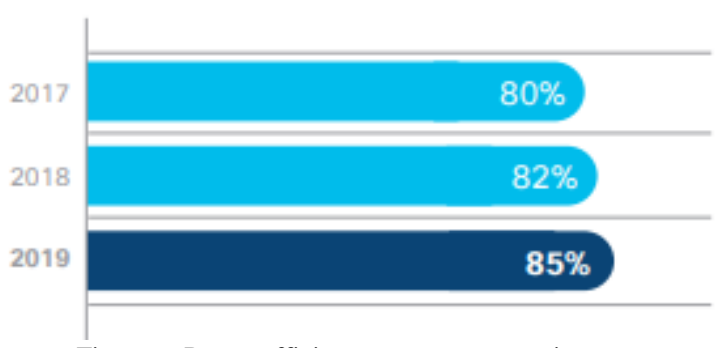

Figure 6: Power efficiency, source: www.cisco.com

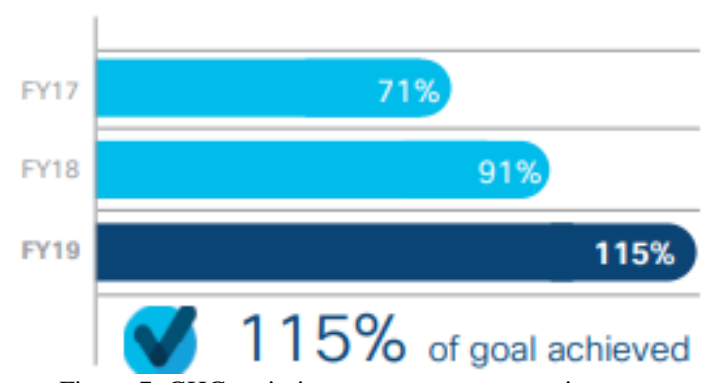

Figure 7: GHG emissions cut, source: www.cisco.com

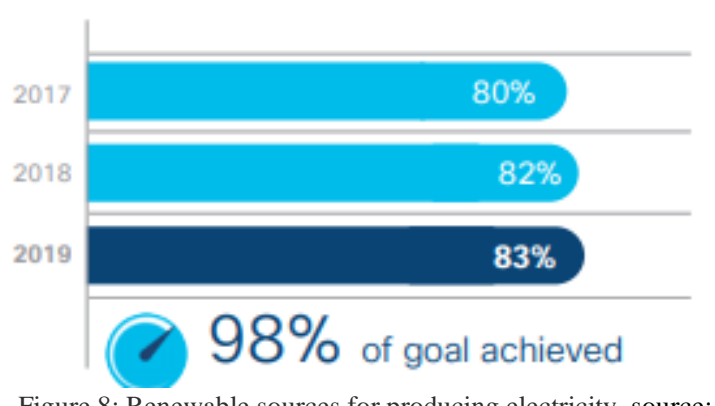

Figure 8: Renewable sources for producing electricity, source: www.cisco.com
Cisco systems use electricity generated from renewable sources for at least 85 percent of our global electricity by FY22. 98\% of goal achievement would be great for this company. Some of other plans and activities based on corporate social responsibility and executive platform by Cisco systems: 1) cisco celebrates Earth Day with relaunch of Product Takeback and Reuse program Research Triangle Park: Update on our environmental progress; 2) stepping up our work on circularity; 3 ) inside Cisco's efforts to manage minerals in our supply chain; 4) live from Davos: CDP and Corporate Knights Highlight Global Sustainability Leaders; 5) Earth Day: What Makes Cisco a Sustainability Leader? 5) cisco is \#2 on Barron's 100 Most Sustainable Companies Ranking. The last 2 items are related to executive platform and the others related to corporate social responsibility. Based on corporate social responsibility Using technology to improve lives around the world is one of the Cisco systems responsibilities. The company has a universal award and the winners of the Cisco Global Problem Solver Challenge are using technology to improve healthcare, increase farmers' incomes, fight climate change, and more (Corporate Social Responsibility Report, 2019). Also, Cisco Systems Company has some key performance metrics in environment: 1) $100 \%$ of electricity used at North American facilities is generated from renewable energy sources; 2) $19.4 \mathrm{GWh}$ of energy avoided in our internal operations through energy efficiency and renewable energy projects; 3) more than 600 employees are members of the Cisco Green Team Network; and 4) 191.5 metric tonnes of used electronics collected at Recycle IT Day 2019.

\section{Conclusion}

The high-tech companies are work in a complex and fast-moving environment. (McGrath, 2010). Strategic planning to generate the flexibility and speed of change necessary for firms to maintain environmental fitness over time would be one of essential part of strategy in tech companies. Cisco Systems has navigated new business models over the last decade, which is based on innovations and also consider many aspects of businesslike environmental protection and social responsibility. In fact, this company not only supports other companies and even governments to achieve their financial goals but save the environment by some green policies and some creative solutions. In addition, for individuals, when people use the modern platform like WebEx (Videoconference) rather than traditional methods, they can save more money and time and save the environment as well. For example, they do not use public or private transportation, so it would decrease greenhouse gas emissions. There are several benefits that we can find for tech companies and it would be necessary to change business models of more businesses toward them.

\section{References}

Sheth, J. (2020). Business of business is more than business: Managing during the Covid crisis. Industrial Marketing Management Journal, Volume 88, , Pages 261-264.

Jackson, S., \& Bourne, D. J. (2020). Can an online coaching programme facilitate behavioural change in women working in STEM fields? International Coaching Psychology Review, 15(1), 21. 
Williamson, B., Eynon, R., \& Potter, J. (2020). Pandemic politics, pedagogies and practices: digital technologies and distance education during the coronavirus emergency, Journal of Learning, Media and Technology, Volume 45, Issue 2.

EdSurge. (2020). "Analysts Watch for Coronavirus Impact on Edtech Stocks." EdSurge, March 5, https://www.edsurge.com/news/2020-03-05-publicmarkets-watch-for-coronavirus-impact-on-edtech-stocks.

Calton, B., Abedini, N., \& Fratkin, M. (2020). Telemedicine in the time of coronavirus. Journal of Pain and Symptom Management, Volume 60, Issue 1, Pages 12-14.

Kitchin, R. (2020). Using digital technologies to tackle the spread of the coronavirus: Panacea or folly. The Programmable City Working Paper 44. Available at: http://progcity. maynoothuniversity. ie/wpcontent/uploads/2020/04/Digital-tech-spread-of-

coronavirus-Rob-Kitchin-PC-WP44. pdf (accessed on 1 May 2020).

Groeger, L., Bruce, K., \& Rolfe, I. (2019). Adapt fast or die slowly: Complex adaptive business models at Cisco Systems. Industrial Marketing Management, 77, 102-115.

Cisco Partner Group, (2010). Cisco Partner Group Cisco's partners, Cisco, San Jose, Available at http://www.cisco.com/c/en/us/partners.html/aboutus, Accessed 11th Jan 2012.

Cisco annual report (2019). Defining the future of the internet Based on Cisco website (https://www.cisco.com/).

Corporate Social Responsibility Report (2019). Based on Cisco website (https://www.cisco.com/).

McGrath, (2010). R.G. McGrath Business models: A discovery driven approach Journal of Long Range Planning, 43 (2010), pp. 247-261.

Chen, R. R., Ravichandar, R., \& Proctor, D. (2016). Managing the transition to the new agile business and product development model: Lessons from Cisco Systems. Business Horizons, 59(6), 635-644.

Chatterjee, S., Narayanan, V., \& Malek, W. (2016). How strategy execution maps guided cisco system's sales incentive compensation plan. Journal of Strategy \& Leadership, Vol. 44 No. 6, pp. 25-34. 